\title{
Nitrogen Mustard Prodrug PR-104
}

National Cancer Institute

\section{Source}

National Cancer Institute. Nitrogen Mustard Prodrug PR-104. NCI Thesaurus. Code C61590.

A non-toxic, small-molecule, hypoxia-activated, 3,5-dinitrobenzamide nitrogen mustard pre-prodrug with potential antitumor activity. Upon intravenous administration, PR-104 is converted by systemic phosphatases to the alcohol intermediate PR-104A, which is reduced to form the active DNA-crosslinking mustard species hydroxylamine PR-104H intracellularly under hypoxic conditions. PR-104H specifically crosslinks hypoxic tumor cell DNA, resulting in the inhibition of DNA repair and synthesis, cell-cycle arrest, and apoptosis in susceptible hypoxic tumor cell populations while sparing normoxic tissues. 